\title{
STUDIES ON RENIN : THE DURATION OF THE PRESSOR EFFECT OF LARGE DOSES IN CONSCIOUS NORMAL AND RENALLY ABNORMAL DOGS. OBSERVATIONS ON ANESTHETIZED AND UREMIC DOGS, AND THE ANAPHYLACTIC AND PATHOLOGICAL EFFECTS OF PIG RENIN
}

\author{
By LOUIS LEITER AND LILLIAN EICHELBERGER \\ WITH THE TECHNICAL ASSISTANCE OF MICHAEL ROMA \\ (From the Lasker Foundation for Medical Research and the Department of Medicine of the \\ University of Chicago, Chicago)
}

(Received for publication March 31, 1942)

The following investigation was started on the assumption that the injection of renin in adequate amounts might have a greater effect in dogs with experimental renal "ischemia" of the Goldblatt type than in normal dogs, provided that endogenous renin were responsible for the experimental hypertension. Trained, unanesthetized dogs were used in order to eliminate the disturbing effects of anesthesia on vasomotor regulation. Constriction of one or both renal arteries, partial obstruction of one ureter, single nephrectomy, and combinations of these procedures were carried out on a series of dogs to furnish the background of renal abnormality. Homologous and heterologous (pig) kidney $^{1}$ extracts were injected repeatedly into normal and renally abnormal dogs, in single or multiple doses, or as continuous injection by means of a pump. For purposes of comparison, renin was also injected into a series of uremic dogs and a group of anesthetized, renally normal dogs. The use of heterologous. renin furnished observations on foreign protein reactions and certain pathological changes.

\section{METHODS}

Preparation of kidney extracts. After removal from the animal, the kidneys were placed immediately on carbon dioxide snow and packed in the ice overnight. The following morning the frozen kidneys were weighed, allowed to soften, and then ground into a volume of 154 mM. $\mathrm{NaCl}$, equivalent to 4 times the total weight of the kidney tissue. Next, the mixture of ground kidneys and saline was placed in quart jars and shaken on a mechanical shaker for 30 minutes, after which the contents were strained through several thicknesses of gauze. The fil-

1 We are deeply indebted to Dr. David Klein, Wilson Laboratories, Chicago, for the pig kidneys used in this study and for some of the extracts. trates from the separate extractions were mixed in one large container for the purpose of obtaining a single solution. This solution was placed in $60 \mathrm{cc}$. centrifuge tubes and heated in a $55^{\circ} \mathrm{C}$. constant temperature bath for 20 minutes, the contents being stirred intermittently (1). The tubes were removed immediately and centrifuged, after which the clear filtrate was decanted (Step 1).

Two hundred and fifty cc. lots of the filtrate were placed in "Visking" cellulose sausage casings (size $1 \%$ in.), and fanned to dryness, which required about 12 hours. The dried casings with contents were kept in vacuum desiccators over $\mathrm{H}_{2} \mathrm{SO}_{4}$ until ready for use. The dried casings when needed were cut into one inch lengths, placed in a large beaker and water added to dissolve the dried residue. The casing strips were then squeezed out and removed (Step 2). Five-tenths $\mathrm{N} \mathrm{HCl}$ was added to the dark brown solution to a final $\mathrm{pH}$ of 4.2 to 4.3 , a heavy precipitate separating. After centrifugation, the filtrate was placed in $50 \mathrm{cc}$. centrifuge tubes and heated in a $55^{\circ} \mathrm{C}$. constant temperature bath for 10 minutes, the contents being stirred every few minutes. After centrifugation, the centrifugate was placed in a casing and dialyzed against water overnight in the ice room, a heavy precipitate separating. The next morning the bag was emptied and the mixture centrifuged (Step 3). An equal volume of saturated ammonium sulfate was added to the clear filtrate. The precipitate was collected by centrifugation. If a further purification is required, the ammonium sulfate precipitation can be repeated. The final precipitate was dissolved in water, placed in a casing, and dialyzed against water overnight. The following morning the casing was opened, the contents centrifuged, and the clear, nearly colorless filtrate was diluted (Step 4). One cubic centimeter of the final solution corresponded to 20 grams of kidney.

Most of the extracts were analyzed for total nitrogen by the micro Kjeldahl method (2).

Measurement of blood pressure. The dogs selected for this work were tractable animals which could be trained to lie quietly for an hour or two on a board with their legs tied. The weights of nearly all the dogs fell between 9 and $15 \mathrm{kgm}$., and their control mean blood pressures, between 110 and $140 \mathrm{~mm}$. $\mathrm{Hg}$. The mean blood pressure was recorded on a kymograph by means of a mercury 
manometer, connected through a large glass cannula with a gauge 18 needle introduced, by direct puncture, into a femoral artery. Sodium citrate solution, 2.5 per cent, was used as the anti-coagulant in the system. Ordinarily, the blood pressure tracing could be run for 10 or 15 minutes with each arterial puncture. In many instances, records of 20 to 30 minutes, at times 40 to 60 minutes, were obtained before a clot obstructed the needle. During the sharp rises in blood pressure resulting from the injection of renin or in the course of the longer tracings, small amounts of citrate solution were momentarily introduced into the cannula, from the pressure bottle, to prevent coagulation. Before the injection of renin, sufficient time was allowed for the blood pressure to be stabilized.

The animals were carefully observed as to changes in heart rate, respiration, nervous behavior, or other symptoms. Blood pressure records from experiments unsatisfactory because of restlessness of the animal, difficult arterial punctures, foreign protein reactions of some severity, or other extraneous vasomotor factors, have been excluded from the results. On the basis of experience, the blood pressure was considered to have returned to the control level when it was within 10 or $15 \mathrm{~mm}$. of the original reading. A residual elevation of 20 to $25 \mathrm{~mm}$. was considered as borderline. Residual elevations of 30 or more $\mathrm{mm}$. were considered as significant hypertension if observed at 60 or more minutes after the end of the injection of renin.

Operative procedures. The constriction of renal arteries was carried out according to the Goldblatt technic (3). Constriction of the ureter to produce hydronephrosis was accomplished by means of a Goldblatt clamp or by the technic previously described (4). Nembutal anesthesia was used in all but a few dogs.

\section{RESULTS}

Pressor responses to single doses of renin. Figure 1 illustrates the pressor effects of single doses in 24 representative experiments, 11 of which were on normal dogs, and 13 on dogs with renal abnormalities. The amount of renin injected was enough to produce a rise of at least 50 to $60 \mathrm{~mm}$. of mercury in the mean femoral blood pressure. There was little difference in the immediate response of a renally normal and abnormal dog to single moderate or large doses of dog or pig renin if allowance was made for differences

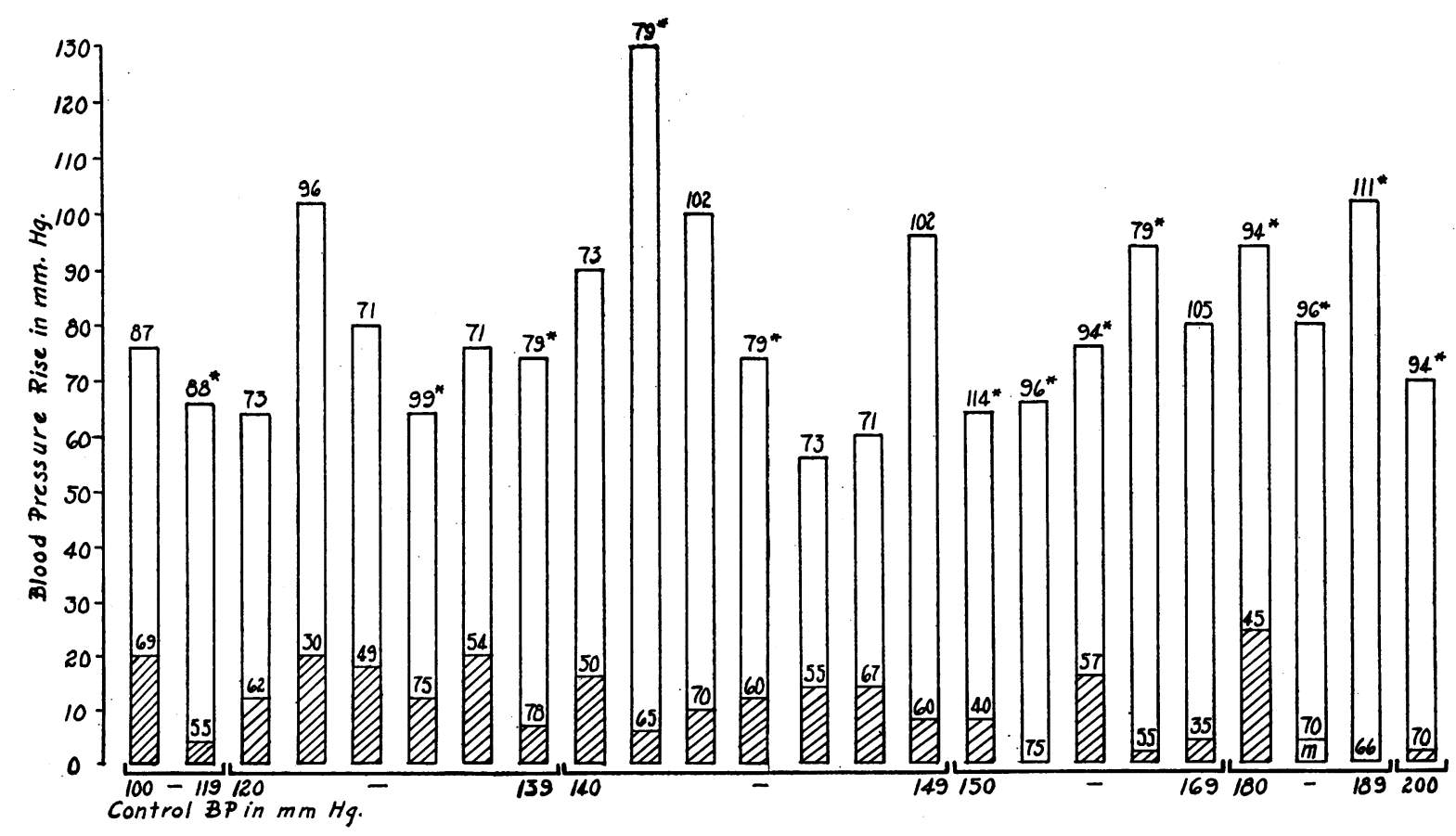

Fig. 1. Normal Duration of Pressor Effect of Moderate or Large Single Doses of Renin in Normal and Renally Abnormal Dogs

Each column represents a single experiment on the dog whose number is listed above it. The asterisk indicates a dog with abnormal kidneys, i.e., constriction of artery or ureter, or nephrectomy. The height of the column is the peak rise in blood pressure, shortly after the injection. The horizontal line in the lower part of each column shows the level of the residual hypertension at the time, in minutes, after the injection denoted by the figure above the bar. The letter " $\mathrm{m}$ " indicates a minus value. 
TABLE I

The pressor effect of large single doses of renin in normal and renally abnormal dogs

\begin{tabular}{|c|c|c|c|c|c|c|c|c|}
\hline \multirow{3}{*}{$\begin{array}{c}\text { Dog } \\
\text { num- } \\
\text { ber }\end{array}$} & \multicolumn{2}{|c|}{ Kidney extract } & \multicolumn{4}{|c|}{ Blood pressure } & \multirow{2}{*}{\multicolumn{2}{|c|}{$\begin{array}{l}\text { Renal ab- } \\
\text { normality }\end{array}$}} \\
\hline & & & \multirow{2}{*}{$\begin{array}{l}\text { Con- } \\
\text { trol }\end{array}$} & \multicolumn{3}{|c|}{ Elevation } & & \\
\hline & $\begin{array}{l}\text { Nitro- } \\
\text { gen }\end{array}$ & $\underset{\text { jected }}{\text { In- }}$ & & Peak & $\mathrm{Te}$ & minal & Left & Right \\
\hline 73 & $\begin{array}{c}\text { mgm. } \\
\text { per } c c . \\
9.5\end{array}$ & $\begin{array}{l}c c . \\
5^{*}\end{array}$ & $\begin{array}{c}\underset{H g}{m} . \\
140\end{array}$ & $\begin{array}{r}\underset{H_{g}}{m} . \\
90\end{array}$ & $\begin{array}{c}\underset{H g}{m} . \\
16\end{array}$ & $\begin{array}{c}\text { minutes } \\
50\end{array}$ & \multicolumn{2}{|c|}{$\begin{array}{c}\text { nephrectomy } \\
\text { or clamps } \\
\text { None }\end{array}$} \\
\hline 102 & 0.97 & $\begin{array}{l}4 \\
3.5\end{array}$ & $\begin{array}{l}142 \\
146\end{array}$ & $\begin{array}{r}100 \\
96\end{array}$ & $\begin{array}{r}10 \\
6\end{array}$ & $\begin{array}{l}70 \\
60\end{array}$ & \multicolumn{2}{|c|}{ None } \\
\hline 79 & 0.54 & 4 & 140 & 130 & 6 & 65 & \multicolumn{2}{|l|}{$\mathbf{N}+$} \\
\hline 88 & $\begin{array}{l}1.05 \\
0.31\end{array}$ & $\begin{array}{c}20 * * \\
4 \\
6\end{array}$ & $\begin{array}{l}104 \\
114 \\
146\end{array}$ & $\begin{array}{r}104 \\
100 \\
92\end{array}$ & $\begin{array}{l}22 \\
14 \\
22\end{array}$ & $\begin{array}{l}60 \\
82 \\
60\end{array}$ & \multicolumn{2}{|l|}{$\begin{array}{l}\mathbf{U} \\
\mathbf{U}\end{array}$} \\
\hline 111 & 2.70 & 9 & 186 & 102 & 0 & 66 & \multirow[t]{2}{*}{$\mathbf{U}$} & $\mathbf{A}$ \\
\hline 99 & 0.97 & 2.5 & 102 & 96 & 20 & 80 & & $\mathbf{A}$ \\
\hline 69 & 1.05 & $20^{* * *}$ & 172 & 90 & 22 & 60 & $\mathbf{A}$ & $A ; U$ \\
\hline 94 & 0.31 & 6 & 148 & 132 & 42 & 60 & $\mathbf{A}$ & \\
\hline 68 & $\begin{array}{r}9.5 \\
10.5\end{array}$ & $\begin{array}{l}4^{*} \\
4^{*}\end{array}$ & $\begin{array}{l}140 \\
150\end{array}$ & $\begin{array}{l}140 \\
110\end{array}$ & $\begin{array}{l}30 \\
40\end{array}$ & $\begin{array}{l}90 \\
80\end{array}$ & $\mathbf{N}$ & $A ; U$ \\
\hline
\end{tabular}

* Dog kidney extract carried through 2 stages of preparation. ** Dog kidney extract carried through 4 stages of preparation. $+\mathrm{N}=$ Nephrectomy; $U=$ Ureter; $\mathrm{A}=$ Artery.

in the control blood pressure levels in the 2 groups of dogs. The duration of the pressor effect was also similar in the 2 series, the blood pressure returning to the control level in 40 to 60 minutes. It should be noted that, for practical reasons, time recorded for the return of the blood pressure to the control level was not necessarily the minimum figure.

The pressor effect of very large single doses of renin, manifested in peak rises of 90 to $140 \mathrm{~mm}$., is illustrated in Table I. In 6 experiments on 2 normal and 3 renally abnormal dogs, the blood pressure returned to the control level within an hour. Borderline residual elevations of 20 to 26 $\mathrm{mm}$. were recorded in 3 with bilateral constriction of arteries or ureters. Residual hypertension of significant degree, 30 to $42 \mathrm{~mm}$. at 60 to $90 \mathrm{~min}$ utes after the injection of renin, occurred in 2 dogs: Dog 68 with a nephrectomy and both artery and ureter constricted in the remaining kidney, and Dog 94 with one artery constricted.

Pressor responses to multiple doses of renin. The effect of multiple injections of potent doses of renin varied with the amount of the individual dose, the time interval between injections, and other factors. Tables II and III and Figures 2 and 3 illustrate the salient features. Prolonged duration of renin activity in certain renally abnormal dogs was first noted in response to multiple injections of kidney extract.

In general, the injection of several doses of renin, within a total period of 10 to 20 minutes, produced about the same ultimate effect as a single large dose. When 10 or more minutes elapsed between injections, the intervening hypertensive plateau was better maintained in both normal and renally abnormal dogs, but in all of the former, and in the milder types of the latter, the blood pressure was recorded at or near the control level within 30 to 80 minutes after the last dose of renin.

However, a prolongation of renin action was demonstrated in a delayed return of the blood pressure to the control level after the last injection in dogs with repeated bilateral clamping of the renal arteries, constriction of one or both arteries and one ureter, or with constriction of artery or ureter to one kidney and opposite nephrectomy (Table III, Figure 3). The injection of multiple doses of renin in these animals resulted in a hypertensive plateau of 40 to $78 \mathrm{~mm}$. Residual elevations of 28 to $66 \mathrm{~mm}$. were recorded at periods of 57 to 114 minutes after the last dose of renin.

Pressor responses to continuous injection of renin. The effects obtained from multiple doses of renin were, on the whole, duplicated in experiments involving the continuous injection of renin (Tables II, III ; Figures 4, 5). The renin was, with few exceptions, injected undiluted or in a dilution of 1 to 2 . The rate and duration of the injection were varied comparably in normal and abnormal dogs, in so far as practicable. The exclusion of experiments with anaphylactic reactions has limited the data on the various groups of dogs shown in the tables and figures, although the general features of the pressor response were similar.

The continuous injection in 6 normal dogs of 0.2 to $1.2 \mathrm{cc}$. of renin per minute over a period of 39 to 94 minutes, resulted in the maintenance of a hypertensive plateau averaging from 20 to $34 \mathrm{~mm}$. in $5 \mathrm{dogs}$, and $52 \mathrm{~mm}$. in $1 \mathrm{dog}$. The first 20 minutes of the blood pressure record was not included in the "plateau" but considered as the effect of the initial dose of renin. Upon cessation of the injection, the blood pressure returned 
TABLE II

The normal duration of the pressor effect of multiple doses or continuous injection of renin in representative normal and renally abnormial dogs

\begin{tabular}{|c|c|c|c|c|c|c|c|c|c|c|c|c|c|}
\hline \multirow{4}{*}{$\begin{array}{r}\substack{\text { Dog } \\
\text { num- } \\
\text { ber }} \\
73\end{array}$} & \multirow{4}{*}{$\frac{\begin{array}{c}\text { Kidney } \\
\text { extract } \\
\text { nitrogen }\end{array}}{\text { mgm. per cc. }}$} & \multicolumn{5}{|c|}{ Kidney extract injected } & \multicolumn{5}{|c|}{ Blood pressure } & \multirow{2}{*}{\multicolumn{2}{|c|}{ Renal abnormality }} \\
\hline & & \multirow{3}{*}{$\begin{array}{c}\text { Initial } \\
c c . \\
8^{*}\end{array}$} & \multirow{2}{*}{\multicolumn{2}{|c|}{ Multiple }} & \multirow{3}{*}{$\begin{array}{c}\begin{array}{c}\text { Contin- } \\
\text { uous }\end{array} \\
\text { cc. }\end{array}$} & \multirow{4}{*}{\begin{tabular}{|c|} 
Time \\
minutes \\
18 \\
10
\end{tabular}} & \multirow{3}{*}{$\begin{array}{c}\text { Control } \\
\underset{\substack{\boldsymbol{M} \boldsymbol{g} \\
\mathbf{1 3 0}}}{\mathbf{1 3}}\end{array}$} & \multicolumn{4}{|c|}{ Elevation } & & \\
\hline & & & & & & & & Peak & Platean & & ninal & Left & Right \\
\hline & & & $\begin{array}{c}\text { number } \\
1\end{array}$ & $\begin{array}{c}c c . \\
20\end{array}$ & & & & $\begin{array}{c}\underset{B m}{m g} \\
64\end{array}$ & $\operatorname{mm}_{\mathbf{H}}$ & $\begin{array}{r}\underset{H m}{m} . \\
12\end{array}$ & $\begin{array}{c}\text { minutes } \\
45\end{array}$ & \multicolumn{2}{|c|}{$\begin{array}{l}\text { nephrectomy } \\
\text { or clamps } \\
\text { None }\end{array}$} \\
\hline 96 & 0.31 & 2 & 3 & 6 & & & 130 & 70 & & 20 & 44 & \multicolumn{2}{|c|}{ None } \\
\hline 99 & 0.45 & 2 & 1 & 8 & & 15 & 104 & 92 & & 24 & 60 & \multicolumn{2}{|c|}{ None } \\
\hline 103 & 0.91 & 2 & 5 & 10 & & 61 & 168 & 62 & 20 & -6 & 45 & \multicolumn{2}{|c|}{ None } \\
\hline 113 & 0.26 & 3 & 4 & 9.5 & & 60 & 122 & 74 & 36 & 14 & 75 & \multicolumn{2}{|c|}{ None } \\
\hline 71 & 0.45 & 2 & 1 & 8 & & 15 & 168 & 100 & & 4 & 50 & $\mathrm{Aq}$ & \\
\hline 64 & 0.91 & 2 & 3 & 6 & & 38 & 220 & 60 & & 16 & 32 & A & \\
\hline 102 & 0.91 & 2 & 5 & 10 & & 56 & 166 & 102 & 35 & 0 & 79 & A & \\
\hline 106 & 0.37 & 2 & 4 & 9 & & 42 & 142 & 88 & 38 & 8 & 74 & $\mathbf{U}$ & A \\
\hline 73 & & 2 & & & $93 t$ & 94 & 126 & 86 & 33 & 20 & 53 & \multicolumn{2}{|c|}{ None } \\
\hline 96 & 0.91 & 2 & & & 15 & 71 & 142 & 90 & 52 & 4 & 39 & \multicolumn{2}{|c|}{ None } \\
\hline 120 & 2.70 & 3.5 & & & 48 & 39 & 134 & 68 & 24 & 14 & 71 & \multicolumn{2}{|c|}{ None } \\
\hline 125 & & 2 & & & $44 \ddagger$ & 65 & 98 & 90 & 20 & 8 & 0 & \multicolumn{2}{|c|}{ None } \\
\hline L 5 & 1.61 & 3.7 & & & $50 \S$ & 48 & 156 & 72 & 25 & -10 & 42 & \multicolumn{2}{|c|}{ None } \\
\hline 128 & & $\begin{array}{l}2 \\
3\end{array}$ & & & $\begin{array}{l}43 \\
45\end{array}$ & $\begin{array}{l}62 \\
71\end{array}$ & $\begin{array}{l}146 \\
152\end{array}$ & $\begin{array}{l}72 \\
58\end{array}$ & $\begin{array}{l}34 \\
27\end{array}$ & $\begin{array}{r}14 \\
2\end{array}$ & $\begin{array}{l}83 \\
19\end{array}$ & \multicolumn{2}{|c|}{ None } \\
\hline 90 & 1.30 & 2 & 2 & 4 & $127 \dagger$ & 299 & 160 & 100 & 30 & 20 & 21 & A & \\
\hline $\begin{array}{l}94 \\
94\end{array}$ & $\begin{array}{l}1.30 \\
0.75\end{array}$ & $\begin{array}{l}2 \\
2 \\
4\end{array}$ & & & $\begin{array}{l}76 \dagger \\
60 \ddagger \\
75 \ddagger\end{array}$ & $\begin{array}{l}88 \\
92 \\
83\end{array}$ & $\begin{array}{l}180 \\
196 \\
178\end{array}$ & $\begin{array}{r}100 \\
80 \\
86\end{array}$ & $\begin{array}{l}40 \\
30 \\
45\end{array}$ & $\begin{array}{l}22 \\
18 \\
26\end{array}$ & $\begin{array}{l}14 \\
63 \\
42\end{array}$ & $\begin{array}{l}\text { A } \\
\text { A } \\
\text { A }\end{array}$ & \\
\hline 104 & 0.26 & 4 & & & $60 \ddagger$ & 102 & 168 & 60 & 34 & 16 & 88 & $\mathrm{U}$ & $\mathbf{N}$ \\
\hline 105 & 2.76 & & & & $\begin{array}{l}64 \\
53\end{array}$ & $\begin{array}{l}81 \\
73\end{array}$ & $\begin{array}{l}228 \\
204\end{array}$ & $\begin{array}{l}92 \\
78\end{array}$ & $\begin{array}{l}24 \\
34\end{array}$ & $\begin{array}{l}16 \\
12\end{array}$ & $\begin{array}{l}45 \\
77\end{array}$ & A & $\mathbf{A}$ \\
\hline 120 & 0.53 & 4 & & & 67 & 52 & 164 & 136 & 30 & -8 & 38 & A & A \\
\hline 121 & 1.61 & 4 & & & 54 & 62 & 196 & 68 & 30 & 4 & 45 & A & A \\
\hline 124 & & 2 & & & 50 & 83 & 162 & 66 & & -4 & 0 & $\mathrm{U}$ & \\
\hline 111 & $\begin{array}{l}0.26 \\
0.53\end{array}$ & $\begin{array}{l}4 \\
4\end{array}$ & & & $\begin{array}{l}50 t \\
28\end{array}$ & $\begin{array}{l}48 \\
41\end{array}$ & $\begin{array}{l}178 \\
140\end{array}$ & $\begin{array}{l}64 \\
54\end{array}$ & $\begin{array}{l}20 \\
36\end{array}$ & $\begin{array}{l}10 \\
18\end{array}$ & $\begin{array}{l}52 \\
59\end{array}$ & $\mathrm{U}$ & A \\
\hline 114 & & & & & 76 & 93 & 174 & 68 & 30 & 8 & 77 & $\mathrm{U}$ & A \\
\hline 115 & & 4 & & & $70 \ddagger$ & 60 & 150 & 100 & 25 & 0 & 5 & A & $\mathbf{U}$ \\
\hline
\end{tabular}

* Dog kidney extract carried through 3 stages of preparation.

t Dilution of 1 volume of kidney extract to 5 volumes.

Dilution of 1 volume of kidney extract to 2 volumes.

Dilution of 1 volume of kidney extract to 1.33 volumes.

$\mathrm{A}=$ Artery; $\mathrm{N}=$ Nephrectomy; $\mathrm{U}=$ Ureter. 
TABLE III

The prolonged pressor effect of multiple doses or continuous injection of renin in certain renally abnormal dogs

\begin{tabular}{|c|c|c|c|c|c|c|c|c|c|c|c|c|c|}
\hline \multirow{5}{*}{$\begin{array}{c}\begin{array}{c}\text { Dog } \\
\text { num- } \\
\text { ber }\end{array} \\
69\end{array}$} & \multirow{5}{*}{$\begin{array}{c}\begin{array}{c}\text { Kidney } \\
\text { extract } \\
\text { nitrogen }\end{array} \\
\text { mgm. per cc. } \\
0.79\end{array}$} & \multicolumn{5}{|c|}{ Kidney extract injected } & \multicolumn{5}{|c|}{ Blood pressure } & \multirow{2}{*}{\multicolumn{2}{|c|}{ Renal abnormality }} \\
\hline & & \multirow{4}{*}{$\begin{array}{c}\text { Initial } \\
c c . \\
4^{*} \\
4^{* *}\end{array}$} & \multirow{2}{*}{\multicolumn{2}{|c|}{ Multiple }} & \multirow{4}{*}{$\begin{array}{c}\begin{array}{c}\text { Contin- } \\
\text { uous }\end{array} \\
\text { cc. }\end{array}$} & \multirow{4}{*}{$\begin{array}{c}\text { Time } \\
\text { minutes } \\
220 \\
220\end{array}$} & \multirow{4}{*}{ 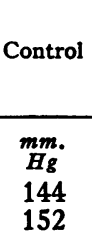 } & \multicolumn{4}{|c|}{ Elevation } & & \\
\hline & & & & & & & & \multirow{3}{*}{ 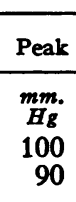 } & \multirow{3}{*}{\begin{tabular}{c|} 
Plateau \\
$\underset{H m .}{m}$. \\
50 \\
78
\end{tabular}} & \multicolumn{2}{|c|}{ Terminal } & Left & Right \\
\hline & & & number & $c c$. & & & & & & $\underset{H \boldsymbol{g}}{\operatorname{mm}}$ & minutes & \multicolumn{2}{|c|}{$\begin{array}{l}\text { nephrectomy } \\
\text { or clamps }\end{array}$} \\
\hline & & & $\begin{array}{l}2 \\
8\end{array}$ & $\begin{array}{r}135 \\
29\end{array}$ & & & & & & $\begin{array}{l}56 \\
76\end{array}$ & $\begin{array}{l}70 \\
57\end{array}$ & $\mathrm{~A} \rrbracket$ & $A ; U$ \\
\hline 88 & 0.35 & 2 & 3 & 7.6 & & 48 & 122 & 102 & 54 & 42 & 114 & $\mathrm{U}$ & \\
\hline 103 & & $4^{*}$ & 29 & 29 & & 79 & 170 & 130 & 50 & 54 & 81 & & \\
\hline 104 & & 3 & 14 & 19 & & 45 & 156 & 74 & 45 & 34 & 70 & $\mathrm{U}$ & $\mathbf{N}$ \\
\hline 68 & 0.91 & 2 & 1 & 2 & 20 & 107 & 142 & 100 & 70 & 54 & 80 & $\mathbf{N}$ & $A ; U$ \\
\hline 103 & 0.82 & 3 & 6 & 6 & $74 \ddagger$ & 150 & 156 & 110 & 60 & 48 & 60 & & \\
\hline $\begin{array}{l}103 \\
103\end{array}$ & $\begin{array}{l}2.7 \\
1.68\end{array}$ & $\begin{array}{l}3 \\
3^{* * *}\end{array}$ & & & $\begin{array}{r}70 \\
101 \\
43\end{array}$ & $\begin{array}{r}140 \\
117 \\
92\end{array}$ & $\begin{array}{l}190 \\
180 \\
152\end{array}$ & $\begin{array}{l}62 \\
76 \\
80\end{array}$ & $\begin{array}{l}44 \\
40 \\
45\end{array}$ & $\begin{array}{l}34 \\
34 \\
40\end{array}$ & $\begin{array}{r}85 \\
118 \\
182\end{array}$ & A & $A ; U$ \\
\hline 90 & & 2 & & & $115 \dagger$ & 103 & 156 & 118 & 43 & 54 & 264 & A & $\mathbf{N}$ \\
\hline 105 & $\begin{array}{l}1.61 \\
0.87\end{array}$ & $\begin{array}{l}3 \\
2.5\end{array}$ & & & $\begin{array}{l}688 \\
88^{* *}\end{array}$ & $\begin{array}{l}93 \\
94\end{array}$ & $\begin{array}{l}200 \\
166\end{array}$ & $\begin{array}{r}136 \\
96\end{array}$ & $\begin{array}{l}45 \\
50\end{array}$ & $\begin{array}{l}34 \\
42\end{array}$ & $\begin{array}{r}125 \\
76\end{array}$ & A & A \\
\hline 111 & 0.53 & 3 & & & 124 & 233 & 124 & 64 & 60 & 32 & 97 & $\mathrm{U}$ & A \\
\hline 126 & 0.61 & $\begin{array}{l}3^{*} \\
3\end{array}$ & & & $\begin{array}{l}47 \\
75\end{array}$ & $\begin{array}{l}103 \\
141\end{array}$ & $\begin{array}{l}152 \\
146\end{array}$ & $\begin{array}{l}64 \\
96\end{array}$ & $\begin{array}{l}60 \\
60\end{array}$ & $\begin{array}{l}28 \\
44\end{array}$ & $\begin{array}{l}57 \\
75\end{array}$ & A & \\
\hline 127 & 1.35 & 3 & & & 65 & 69 & 150 & 110 & 45 & 48 & 51 & A & \\
\hline
\end{tabular}

* Dog kidney extract carried through 1 stage of preparation.

** Dog kidney extract carried through 2 stages of preparation.

*** Dog kidney extract carried through 4 stages of preparation.

t Dilution of 1 volume of kidney extract to 5 volumes.

$\ddagger$ Dilution of 1 volume of kidney extract to 2 volumes.

Dilution of 1 volume of kidney extract to 1.33 volumes.

I $\mathrm{A}=$ Artery; $\mathrm{N}=$ Nephrectomy; $\mathrm{U}=$ Ureter.

to the control level as quickly as after the end of any single moderate dose of renin (Table II; Figure 4).

Similar pressor responses were obtained upon the continuous injection of renin in 11 dogs with various renal abnormalities (Table II). A hypertensive plateau of 30 to $45 \mathrm{~mm}$. was maintained in 10 experiments, of 20 to $25 \mathrm{~mm}$. in 3 experiments. The blood pressure was recorded at or near the control level within the time limits observed in the normal dogs. There was no abnormal duration of renin pressor action in this group of hypertensive dogs.

Prolongation of renin pressor activity after pump injection was typically illustrated in 5 dogs with the more severe experimental renal abnor- malities, but also occurred in 2 dogs shortly after constriction of 1 renal artery (Table III ; Figure 5). The renal disturbance consisted of bilateral constriction of the arteries, with additional hydronephrosis or unilateral nephrectomy in 4 dogs. A hypertensive plateau averaging 40 to $70 \mathrm{~mm}$. above the control level was maintained during the injection. The blood pressure was still elevated 28 to $54 \mathrm{~mm}$. above the pre-injection figure at 51 to 264 minutes after the end of the injection of renin. The prolonged renin hypertension was reproducible in repeated experiments on the same dog ( Table III). Sensitization to pig renin probably played a part in some of the negative experiments on Dog 105.

Pressor responses to renin in anesthetized dogs. 


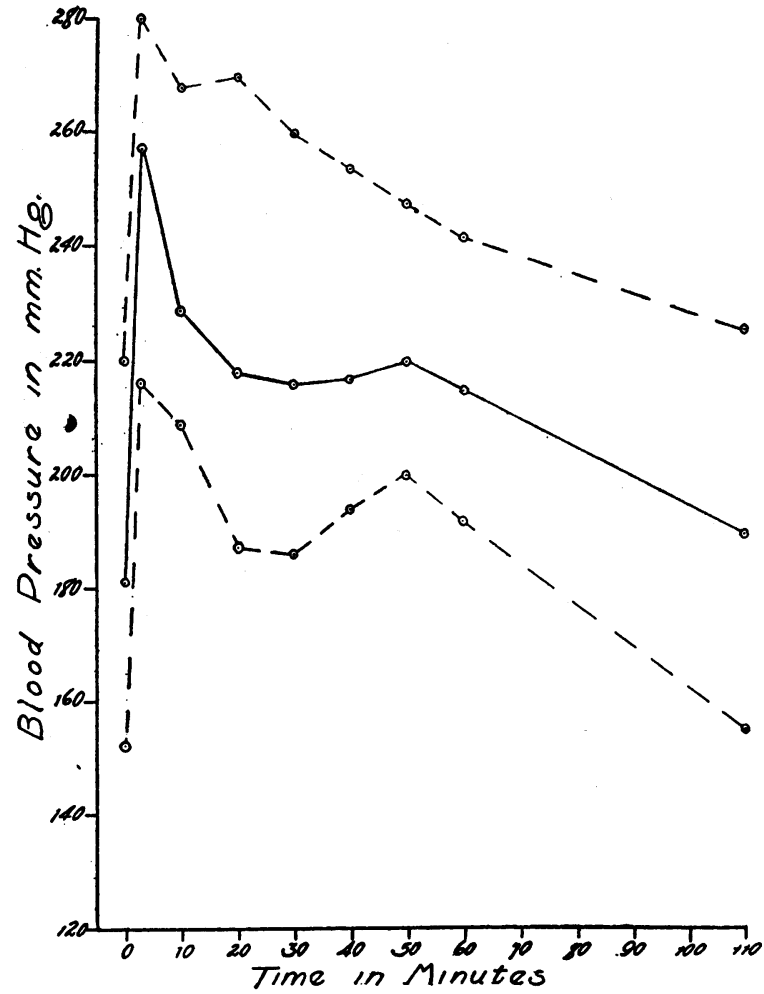

Fig. 2. The Normal Pressor Effect of Multiple Doses of Renin in Renally Abnormal Dogs

The solid line indicates the average response in 5 experiments. The dotted lines indicate the minimum and maximum range in this series. The interval of time between the first and the last injection ranged from $42 \mathrm{~min}$ utes to 80 minutes.

The small series of experiments listed in Table IV is representative of a general reaction pattern. The dosage of renin used was comparable to the amount given to conscious dogs. Even after a single moderate dose of renin, the normal dog under barbiturate anesthesia shows a hypertensive plateau which may persist for a long time. Multiple injections of renin at proper intervals in the anesthetized, renally normal dog can produce successively higher plateaus and prolonged residual hypertension after the last injection. Continuous injection of renin has not been tried.

Pressor responses to renin in conscious uremic dogs. As shown in Table $\mathrm{V}$, the injection of homologous renin in single or repeated doses produced a prolonged hypertension in 5 out of 8 nonhypertensive, uremic dogs. Inadequate dosage or improper timing of the injections may have been

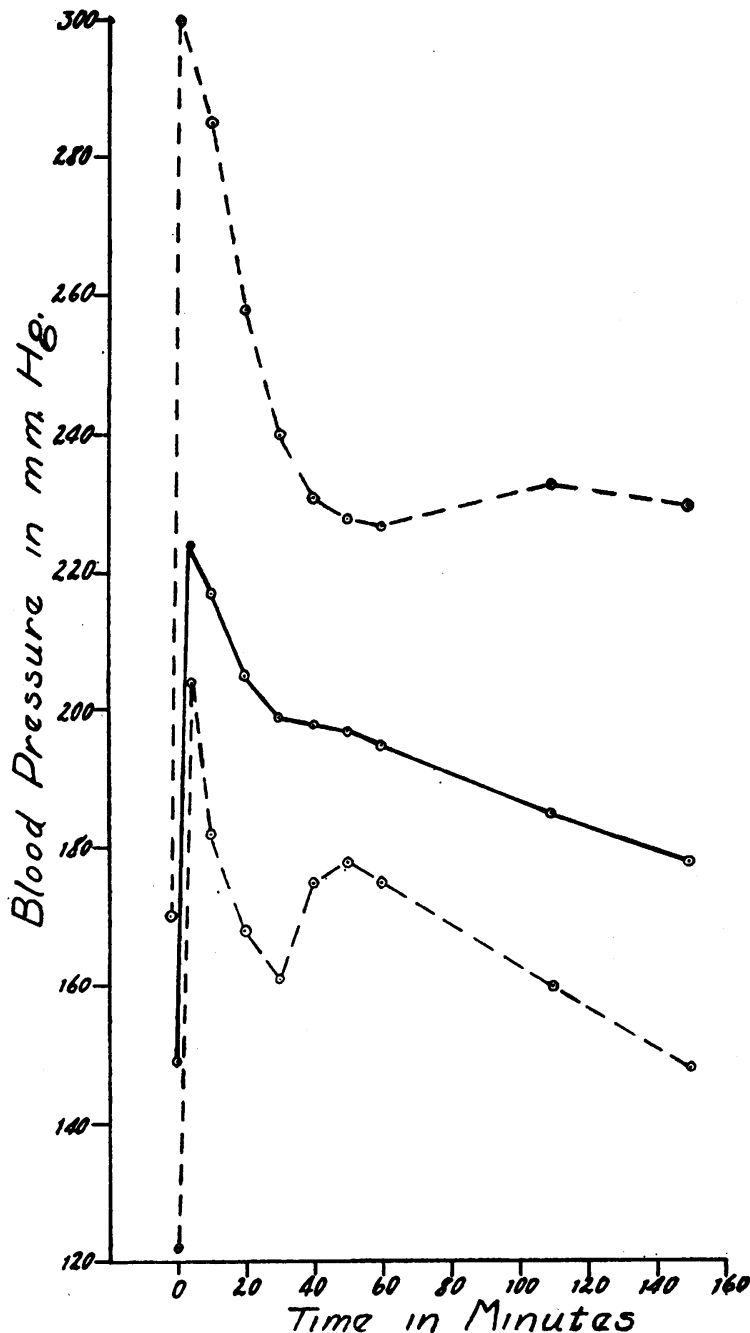

Fig. 3. The Prolonged Pressor Effect of Multiple Doses of Renin in Renaliy Abnormal Dogs

The solid line indicates the average response in 5 experiments. The dotted lines indicate the minimum and maximum range in the series. The interval of time between the first and the last injection ranged from $45 \mathrm{~min}$ utes to 94 minutes.

responsible for the absence of prolonged residual hypertension in the other 3 dogs. The severely hypertensive uremic Dogs 90 and 107 failed to maintain a pressor plateau during or between injections of renin and showed no prolonged residual elevation. Both animals had numerous cardiac hemorrhages and necroses at autopsy. Dog 102, which also had marked hypertension, maintained a pressor plateau of only $20 \mathrm{~mm}$.

Tachyphylaxis to renin. This was a constant 


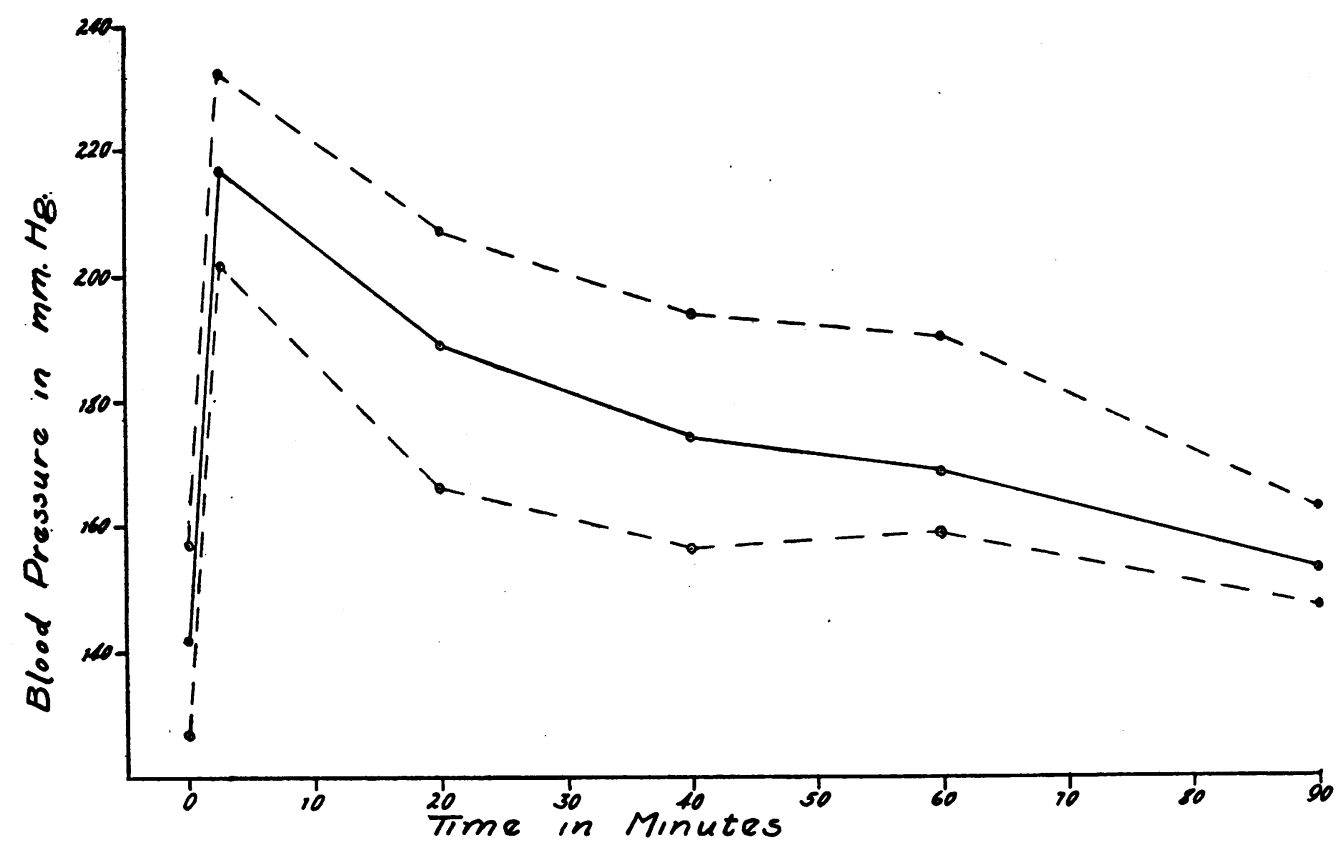

Fig. 4. The Normal Duration of the Pressor Effect of Continuous (Pump) Injection of RENIN IN NoRMal Dogs

The solid line indicates the average response in 5 experiments. The dotted lines indicate the minimum and maximum range in the series. The injection of renin was maintained for periods varying from 39 minutes to 94 minutes from zero time.

phenomenon regardless of the renal status, the blood pressure of the animal, or the number of experiments on the same dog. The decreasing pressor response on repeated injections of renin varied somewhat with the dosage and the intervals. Occasionally, after several moderate doses of renin, no subsequent pressor response occurred unless the hypertensive plateau had subsided. In the conscious dog, in contrast to the anesthetized dog, successive doses of renin rarely produced step-like rises in the intervening plateaus. However, when renin was injected by pump, changes in the level of the pressor plateau could at times be effected by modifying the rate of injection. When weak, presumably impure extracts were used, tachyphylaxis was apparently accentuated. The failure of a later dose of renin to produce a rise of more than 10 to $20 \mathrm{~mm}$. in the hypertensive plateau did not exclude a prolonged residual effect, as measured by the duration of significant hypertension or the time required for the return of the blood pressure to the control level. The amount of renal extract previously injected was appar- ently the chief factor in this lag, which rarely exceeded 2 or 3 hours.

Anaphylaxis to renin. The use of heterologous pig renin led to anaphylactic reactions in many dogs subjected to repeated, experiments. There was only 1 fatality, Dog 105, and in this case there was no immediate shock. The anaphylactic response was best observed on the blood pressure tracing. After the injection of renin in a sensitized dog, the usual rise and peak in the blood pressure occurred. However, the ordinary bradycardia soon gave way to tachycardia, and a more or less steep fall in blood pressure took place within the next few minutes. The level finally reached was above the control value in the mildest reactions, at or near the control blood pressure in the mild reactions, and at varying degrees of hypotension in moderate or severe anaphylaxis. The time of recovery was usually directly related to the depressor response, varying from a few minutes to a half hour or more. After the milder reactions, the experiment could usually be continued and more renin injected without evident 


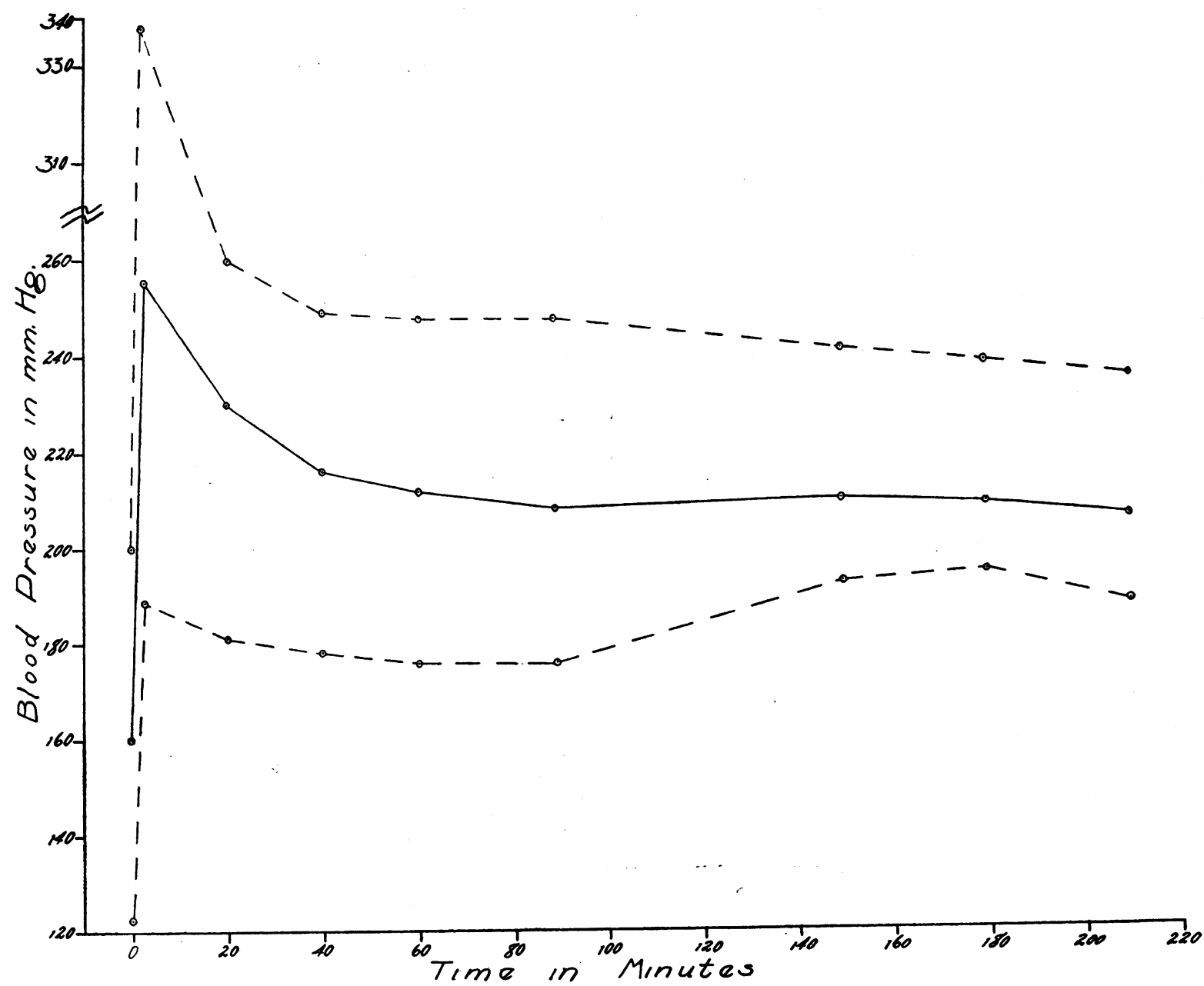

Fig. 5. The Prolonged Duration of the Pressor Effect of Continuous (Pump) Injection of Renin in Dogs with Bilateral Renal Abnormality

The solid line indicates the average response in 11 experiments. Blood pressures on 9 dogs were recorded for 210 minutes, 1 dog for 180 minutes, and 1 dog for 150 minutes. The injection of renin was maintained for periods varying from 69 minutes to 150 minutes from zero time.

abnormal effects. During the more severe anaphylactic reactions, most of the dogs exhibited salivation, and at times vomiting, restlessness, respiratory disturbances, hyperperistalsis, and defecation of normal or diarrheal feces. Tachycardia was a constant sign and, in the more severe reactions, continued for some time after other symptoms had disappeared.

In general, sensitization to kidney extract was determined by dosage and the intervals between injections. Most of the dogs showed some anaphylaxis after a few injections at $\mathbf{5}$ to $\mathbf{1 5}$ day intervals if one large dose was included. In occa- sional dogs, sensitization was attributable to a large injection of renin, 3 or 4 months previously. The use of kidney extracts weak in pressor activity or high in nitrogen content facilitated the development of the anaphylactic state in dogs previously tolerant of large doses of renin. Desensitization occurred spontaneously in some dogs if a month or two intervened between experiments and if only moderate doses of extract were given. On the other hand, it was possible to desensitize several dogs by producing a mild or moderate anaphylactic reaction a few hours to a day preceding the injection of a large amount of renin. No dog became 
TABLE IV

The prolonged pressor effect of renin in normal anesthetized dogs

\begin{tabular}{|c|c|c|c|c|c|c|c|c|c|c|c|}
\hline \multirow{3}{*}{$\begin{array}{c}\text { Dog } \\
\text { number }\end{array}$} & \multirow{4}{*}{$\begin{array}{c}\begin{array}{c}\text { Kidney } \\
\text { extract } \\
\text { nitrogen }\end{array} \\
m g m . \text { per cc. } \\
1.05\end{array}$} & \multicolumn{4}{|c|}{ Kidney extract injected } & \multicolumn{5}{|c|}{ Blood pressure } & \multirow{2}{*}{ Anesthetic } \\
\hline & & Initial & \multicolumn{2}{|c|}{ Multiple } & Time & Control & Peak & Plateau & \multicolumn{2}{|c|}{ Terminal } & \\
\hline & & $c c$. & number & $c c$. & minutes & $\underset{H \boldsymbol{g}}{\operatorname{mm}}$ & $\underset{H \boldsymbol{g}}{m m}$. & $\underset{H \boldsymbol{g}}{m_{\boldsymbol{g}}}$ & $\underset{H \boldsymbol{g}}{m_{\boldsymbol{g}}}$ & minutes & \\
\hline A & & $\begin{array}{l}0.5^{*} \\
2^{*}\end{array}$ & 1 & 1 & 20 & $\begin{array}{l}126 \\
116\end{array}$ & $\begin{array}{l}40 \\
60\end{array}$ & $\begin{array}{l}40 \\
40\end{array}$ & $\begin{array}{l}34 \\
40\end{array}$ & $\begin{array}{l}61 \\
60\end{array}$ & $\begin{array}{l}\text { Ether } \\
\text { Nembutal }\end{array}$ \\
\hline B & 1.05 & $1.5^{*}$ & & & & 114 & 46 & & 28 & 60 & Nembutal \\
\hline C & 1.05 & $2^{*}$ & & & & 104 & 48 & 40 & 32 & 107 & Nembutal \\
\hline $\mathrm{D}$ & & 1.6 & & & & 104 & 120 & 65 & 60 & 50 & Barbital \\
\hline $\mathrm{E}$ & 0.54 & $\begin{array}{l}2 \\
3\end{array}$ & $\begin{array}{l}5 \\
3\end{array}$ & $\begin{array}{r}10 \\
8\end{array}$ & $\begin{array}{l}123 \\
145\end{array}$ & $\begin{array}{r}100 \\
74\end{array}$ & $\begin{array}{r}74 \dagger \\
116 \dagger\end{array}$ & $\begin{array}{l}45 \\
58\end{array}$ & $\begin{array}{l}54 \\
66\end{array}$ & $\begin{array}{l}30 \\
33\end{array}$ & Nembutal \\
\hline
\end{tabular}

* Dog kidney extract.

† Peak occurred with second or later injection.

TABLE $\mathrm{V}$

The pressor effect of renin in conscious uremic dogs

\begin{tabular}{|c|c|c|c|c|c|c|c|c|c|c|c|c|c|c|}
\hline \multirow{4}{*}{$\begin{array}{c}\text { Dog } \\
\text { number }\end{array}$} & \multirow{5}{*}{$\begin{array}{c}\begin{array}{c}\text { Kidney } \\
\text { extract } \\
\text { nitrogen }\end{array} \\
\begin{array}{c}m g m . \text { per cc. } \\
0.99\end{array}\end{array}$} & \multicolumn{5}{|c|}{ Kidney extract injected } & \multicolumn{5}{|c|}{ Blood pressure } & \multirow{2}{*}{\multicolumn{2}{|c|}{$\begin{array}{c}\text { Renal } \\
\text { abnormality }\end{array}$}} & \multirow{3}{*}{$\begin{array}{l}\text { Blood } \\
\text { NPN }\end{array}$} \\
\hline & & \multirow{2}{*}{ Initial } & \multicolumn{2}{|c|}{ Multiple } & \multirow{3}{*}{$\frac{\begin{array}{c}\text { Contin- } \\
\text { uous }\end{array}}{c c .}$} & \multirow{4}{*}{$\begin{array}{c}\text { Time } \\
\begin{array}{c}\text { minutes } \\
107\end{array}\end{array}$} & \multirow{4}{*}{$\begin{array}{c}\text { Control } \\
\underset{c m}{m m_{g}} \\
120\end{array}$} & \multicolumn{4}{|c|}{ Elevation } & & & \\
\hline & & & & & & & & Peak & Plateau & & ninal & Left & Right & \\
\hline & & $c c$. & number & $c c$. & & & & $\underset{H \boldsymbol{g}}{\operatorname{mm}}$ & $\underset{H \boldsymbol{g}}{\mathrm{mm}}$ & $\underset{H \boldsymbol{g}}{\operatorname{mm}}$ & minutes & $\begin{array}{l}\text { nephr } \\
\text { or cl }\end{array}$ & $\begin{array}{l}\text { tomy } \\
\text { mps }\end{array}$ & \\
\hline 74 & & $20 \dagger$ & 3 & 85 & & & & 54 & 24 & 30 & 50 & $\mathrm{~N}$ T & $\mathrm{U}$ & 77 \\
\hline 76 & 10.9 & $4 \ddagger$ & 3 & 10 & & 134 & 106 & 84 & 42 & 48 & 64 & $\mathbf{N}$ & $\mathbf{N}$ & 266 \\
\hline 77 & $\begin{array}{c}0.85 \\
10.5\end{array}$ & $\begin{array}{r}20 \dagger \\
2 \ddagger\end{array}$ & & & & & $\begin{array}{l}120 \\
108\end{array}$ & $\begin{array}{l}80 \\
62\end{array}$ & & $\begin{array}{l}54 \\
56\end{array}$ & $\begin{array}{l}50 \\
61\end{array}$ & $\mathbf{N}$ & $\mathbf{N}$ & \\
\hline 80 & & $2 \ddagger$ & 3 & 6 & & 71 & 108 & 80 & 30 & 26 & 60 & $\mathbf{N}$ & $\mathrm{U}$ & \\
\hline 82 & 0.90 & $40 \dagger$ & 2 & 37 & & 41 & 144 & 56 & & 18 & 94 & $\mathrm{U}$ & $\mathbf{N}$ & 126 \\
\hline 84 & 0.82 & $30 \dagger$ & 3 & 90 & & 25 & 118 & 62 & & 14 & 73 & $\mathrm{U}$ & $\mathrm{U}$ & \\
\hline 85 & 1.24 & $40 \dagger$ & 1 & 30 & & 17 & 130 & 66 & & 16 & 53 & A & A & 101 \\
\hline 87 & 1.05 & $20^{*}$ & & & & & 108 & 132 & 36 & 24 & 96 & $\mathbf{N}$ & $\mathbf{N}$ & 79 \\
\hline 90 & 0.58 & 2 & & & $89 \S$ & 110 & 200 & 66 & 4 & 8 & 57 & A & $\mathbf{N}$ & 58 \\
\hline 102 & 0.83 & 2 & 5 & 10 & & 55 & 204 & 54 & 20 & 10 & 78 & A & A & 114 \\
\hline 107 & 0.36 & 2 & 4 & 6 & & 39 & 200 & 60 & & 8 & 21 & $\mathbf{U}$ & A & 80 \\
\hline
\end{tabular}

* Dog kidney extract carried through 4 stages of preparation.

$\dagger$ Dog kidney extract carried through 1 stage of preparation.

$\ddagger$ Dog kidney extract carried through 2 stages of preparation.

$\$$ Dilution of 1 volume of kidney extract to 5 volumes.

I $\mathrm{N}=$ Nephrectomy; $\mathrm{U}=$ Ureter; $\mathrm{A}=$ Artery.

immune to renin in the sense that it failed to give an immediate pressor response to an intravenous injection of renin. Anaphylactic reactions were never observed in animals receiving homologous renin, whether they were sensitive or not to pig renin.
Pathological changes following injection of heterologous kidney extract. In 15 dogs with experimental renal abnormalities, death occurred within a few days after injections of heterologous renin. Two animals, Dogs 79 and 105, died within a few hours after a large continuous infusion of 
renal extract, the former showing hemoglobinuria. There were acute degenerative changes in the liver and kidneys. In 12 of the remaining 13 dogs; numerous areas of hemorrhage and necroses were present throughout the heart and gastro-intestinal tract, infrequently in the diaphragm and elsewhere. Histologically, the lesions consisted of hyaline degeneration and fibrinoid necrosis of arterioles and capillaries, with interstitial hemorrhage, leukocytic exudation, and focal necrosis of parenchyma. The kidneys were spared, as was skeletal muscle. While 8 dogs had enough renal insufficiency and hypertension to explain the production of this malignant phase, in 4 dogs with clamps on the renal arteries there was not sufficient renal damage nor severe hypertension to account for the lesions. Thus, Dog 138, with clamps on both renal arteries, had a blood NPN of $25 \mathrm{mgm}$. and blood pressure of $168 \mathrm{~mm}$. the day before death; Dogs 119 and 120, with blood pressures of 164 and $178 \mathrm{~mm}$., showed no symptoms of uremia but unfortunately had no NPN determination; Dog 121 was killed 5 months after the last injection of pig renin, was in good health except for hypertension, and showed healed lesions in the right auricle. In these animals, the injection of kidney extract apparently was an important factor in the development of the hemorrhagic lesions. Anaphylaxis to kidney extract could not be correlated with the occurrence of the specific pathological changes. No deaths occurred in normal dogs given pig renin or in renally abnormal dogs given dog renin. It is extremely doubtful that they could have survived the extensive cardiac and gastro-intestinal lesions found in the other animals.

\section{DISCUSSION}

The relationship of renin to experimental renal hypertension has been the subject of much investigation, summarized in recent reviews of the literature $(5,6)$. The purpose of the present study was to determine whether there was an unusual response to renin on the part of dogs with renal hypertension or other renal abnormality. If renin were responsible for renal hypertension, the injection of extra renin might, under certain conditions, be expected to accentuate the pre-existent hypertension.
The results of this investigation on conscious, trained dogs indicate that renin in single, moderate, or large doses produces essentially similar pressor effects in normal and renally abnormal dogs, regardless of their blood pressure level. However, when multiple doses of renin are given at proper intervals or when continuous injection is employed, the dogs with the more extensive renal abnormalities, such as bilateral constriction of the arteries, or of arteries and a ureter, or with the added load of a nephrectomy, maintain a higher pressor plateau during the administration of renin and show a much longer duration of residual hypertension after the end of the injection. These effects are not observed in normal dogs nor in most dogs with constriction of a single artery or ureter, or with a simple nephrectomy. In these animals, multiple or continuous injection of renin results in a moderate hypertensive plateau, but the blood pressure returns to the control level about as rapidly as after a single dose of kidney extract. The failure of large amounts of renin to produce prolonged hypertension consistently in dogs with extensive renal abnormalities may be attributed to several factors: weak or impure renal extracts; mild or unrecognized foreign protein or anaphylactic reactions to heterologous renin; or a very high control blood pressure close to the limit of sustained vasoconstriction in the individual dog. The effect of extensive cardiac hemorrhages in malignant hypertension in counteracting the pressor response to injected renin must also be taken into account.

One may conclude, therefore, that the unanesthetized dog with extensive renal abnormality and varying degrees of hypertension, but without renal excretory failure, is more susceptible to the action of large amounts of renin than is the normal dog or the dog with unilateral renal abnormality. It is not clear at present whether this behavior indicates an insufficient ability on the part of the normal renal parenchyma to counteract or neutralize the pressor activity of the "ischemic" kidney and the exogenous renin $(7,8)$, a decreased "antipressor" content of the animal's blood $(9,10)$, or an increased supply of substrate on which renin must act to produce the effective vasoconstrictor $(11,12)$. Some preliminary observations on the production of "hypertensin" by the action of renin 
upon the plasma of normal and renally abnormal dogs, have not revealed significant differences in the amount of plasma substrate in the various animals (13), although they have confirmed its disappearance or marked diminution shortly after the injection of renin (11).

Certain objections to the renin theory of experimental renal hypertension have been raised (14). They concern, chiefly, the development of tachyphylaxis, the similar pressor response to renin of hypertensive and normal animals, the difficulty of maintaining sustained rises in blood pressure on infusion of renin, and the failure of the blood pressure to fall below the control level in either normal or hypertensive rabbits after tachyphylaxis to renin is established. The last objection is a serious obstacle to the renin theory, if tachyphylaxis is considered solely from the point of view of exhaustion of the plasma substrate necessary for renin activity. However, it has been shown that tachyphylaxis is not merely a problem of renin and substrate (15). Furthermore, little is known of the rate of replenishment of substrate or the amount necessary to permit a continuing renin effect in vivo. Residual renin hypertension can be present in the absence of demonstrable substrate (13). This may simply mean that the in vivo pressor response is a more sensitive criterion than other assay procedures. If, in the intact renal hypertensive animal, the central nervous regulation of the blood pressure is somehow adjusted to the new level (16), this may explain the exact return of the blood pressure to control value after renin tachyphylaxis, since a relatively short period is required to restore substrate for endogenous renin.

If an anti-pressor substance, renin- or angiotonin-inhibitor can be released by normal renal parenchyma (9), the higher pressor plateaus and prolonged residual hypertension produced by injection of renin in renally abnormal dogs may be explained as an impairment of this function. Since prolonged duration of renin activity can occur in renally "ischemic" dogs with only moderate or little hypertension, one must assume a balance between low endogenous renin and inhibitor in these animals, with an inability to produce the latter rapidly in response to a sudden excess of exogenous renin. On this basis, the occurrence of tachyphylaxis may be taken as evidence against the view that a renin- or angiotonin-inhibitor mechanism is largely responsible for this phenomenon.

Whatever the means by which renin pressor activity is kept within moderate limits after the initial rise in the renally normal, conscious dog, a marked impairment of this function occurs in the anesthetized dog, which behaves as though it had extensive renal abnormality. The prolonged pressor plateau after single injections of renin makes it difficult to evaluate the effects of continuous infusion.

The occurrence of anaphylactic reactions in animals receiving repeated injections of heterologous renin has also been observed in the rabbit (17). The sensitization is apparently not carried over to homologous renin. In this respect, the phenomenon differs sharply from the immunological formation of "anti-renin" in hypertensive dogs, injected intramuscularly with heterologous renin (18). Our anaphylactic hypertensive dogs showed no consistent blood pressure reduction that could be interpreted as evidence of immunity to endogenous renin; but the experimental conditions were not such as to favor the development of "anti-renin."

Foreign protein reactions, as distinguished from true anaphylaxis, were observed in the course of continuous infusion of renin in some dogs. They appear chiefly in the blood pressure response in the case of homologous extracts, resulting in a falling curve that may reach the control level at the end of the injection. Similar reactions have been described in rabbits (19). When heterologous kidney extract causes this type of reaction, severe symptoms and, very rarely, death may occur. It is, therefore, difficult to draw conclusions from experiments with poor pressor plateaus. Some of the discrepancies in the literature on renin activity are undoubtedly attributable to neglect of this factor.

The relation of kidney extracts to the pathology of experimental malignant hypertension has been strikingly emphasized in recent studies on nephrectomized dogs (20). The necessary combination of severe renal insufficiency and hypertension in the etiology of the malignant syndrome of renally ischemic animals $(21,22)$, has been questioned as 
the result of experiments on rats, in which only. one renal artery was constricted $(23,24)$. In the present study, there are definite indications that heterologous renin can precipitate cardiac and gastro-intestinal hemorrhages and necroses, in some dogs without severe hypertension or renal insufficiency. The findings have been detailed elsewhere (25).

The role of renin in human hypertension is still a matter of conjecture. It is plausible to assume renin participation in the severe malignant phase, in which renal ischemia and necrosis provide a source for the pressor substance. Release of renin probably occurs after the sudden occlusion of renal arteries (26). The successful treatment of juvenile hypertension by nephrectomy, in cases of unilateral renal disease or vascular lesions of various types (27), strongly suggests interruption of a renin hypertension. However, direct demonstration of a renin mechanism in this small clinical group is not yet available. If the situation in man is at all comparable to experimental hypertension in the rat (24), renin hypertension of unilateral renal origin would sooner or later lead to a vicious circle because of the damaging effect of hypertension, or renin, on the arterioles of the sound kidney. In ordinary "essential" hypertension, without signs of organic renal involvement, there is, at present, no satisfactory evidence for a renin mechanism. Further study of the pressor response of such individuals to adequate dosage of renin should yield interesting data for comparison with the results observed in normotensive human subjects (28).

\section{SUMMARY AND CONCLUSIONS}

1. Trained, conscious dogs, injected with renin intravenously, in single moderate or large doses, sufficient to elevate the mean femoral blood pressure 50 to $100 \mathrm{~mm}$. Hg., gave similar pressor responses whether their kidneys were normal or experimentally abnormal as the result of partial constriction of arteries or ureters, with or without unilateral nephrectomy.

2. Multiple doses of renin, or continuous injection by pump, produced a pressor plateau in renally normal and abnormal dogs, but the blood pressure returned to the control level within an hour after the injection in all of the normal ani- mals and in most of the dogs with unilateral or less extensive bilateral renal lesions.

3. Marked prolongation of renin pressor activity was observed chiefly in dogs with bilateral, experimental, renal abnormalities following multiple doses or continuous injection of kidney extract, free from depressor material.

4. Prolonged duration of renin pressor activity also occurred in anesthetized, renally normal dogs and in the majority of conscious dogs with uncomplicated uremia. Dogs with experimental hypertension and uremia reacted irregularly.

5. Repeated experiments on the same animal with heterologous renin led to the development of anaphylaxis. Dogs sensitized to pig renin reacted normally to dog renin.

6. The pathological lesions of experimental malignant hypertension can be induced or accelerated by the injection of foreign renin, not only in dogs with excessive renal ischemia or necrosis, but in some animals without severe hypertension or uremia.

7. The prolonged effect of renin in conscious dogs with extensive renal abnormality is regarded as evidence in favor of the renin etiology of experimental renal hypertension, and in support of the view that the ratio of normal to abnormal ("ischemic") renal parenchyma is a determining factor in the dog's response to exogenous, as well as endogenous, renin.

8. The relation of renin to human "essential" hypertension remains an open question.

\section{BIBLIOGRAPHY}

1. Landis, E. M., Montgomery, H., and Sparkman, D., The effects of pressor drugs and of saline kidney extracts on blood pressure and skin temperature. J. Clin. Invest., 1938, 17, 189.

2. Campbell, W. R., and Hanna, M. I., Determination of nitrogen by modified Kjeldahl methods. J. Biol. Chem., 1937, 119, 1.

3. Goldblatt, H., Lynch, J., Hanzal, R. F., and Summerville, W. W., Studies on experimental hypertension. The production of persistent elevation of systolic blood pressure by means of renal ischemia. J. Exper. Med., 1934, 59, 347.

4. Eichelberger, L., Experimental hydronephrosis in dogs; composition of blood serum. J. Urol., 1938, 40, 366 .

5. Blalock, A., Experimental hypertension. Physiol. Rev., 1940, 20, 159. 
6. Leiter, L., Kidney. Ann. Rev. Physiol., 1941, 3, 509.

7. Fasciolo, J. C., Action de rein sain sur l'hypertension artérielle par ischémie rénale. Compt. rend. Soc. biol., 1938, 128, 1129.

8. Katz, L. N., Friedman, M., Rodbard, S., and Weinstein, W., Observations on the genesis of renal hypertension. Am. Heart J., 1939, 17, 334.

9. Page, I. H., and Helmer, O. M., Angiotonin-activator, renin- and angiotonin-inhibitor, and the mechanism of angiotonin tachyphylaxis in normal, hypertensive, and nephrectomized animals. J. Exper. Med., 1940, 71, 495.

10. Page, I. H., Vasoconstrictor action of plasma from hypertensive patients and dogs. J. Exper. Med., 1940, 72, 301.

11. Munoz, J. M., Braun-Menendez, E., Fasciolo, J. C., and Leloir, L. F., The mechanism of renal hypertension. Am. J. M. Sc., 1940, 200, 608.

12. Page, I. H., Difference in activating effect of normal and hypertensive plasma on intestinal segments treated with renin. Am. J. Physiol., 1940, 130, 29.

13. Leiter, L., and Eichelberger, L., Studies on "Hypertensin." To be published.

14. Taggart, J., and Drury, D. R., The action of renin on rabbits with renal hypertension. J. Exper. Med., 1940, 71, 857.

15. Page, I. H., On the nature of the pressor action of renin. J. Exper. Med., 1939, 70, 521.

16. Dock, W., Vasoconstriction in renal hypertension abolished by pithing. Am. J. Physiol., 1940, 130, 1.

17. Landis, E. M., Jeffers, W. A., and Shiels, E. H., Pressor effects of homologous and heterologous injections of heated kidney extracts. Am. J. Physiol., 1940, 128, 672.

18. Wakerlin, G. E., and Johnson, C. A., Reductions in blood pressures of renal hypertensive dogs by hog renin. Proc. Soc. Exper. Biol. and Med., 1941, 46, 104.
19. Hill, J. R., and Pickering, G. W., Hypertension produced in the rabbit by prolonged renin infusion. Clin. Sc., 1939, 4, 207.

20. Winternitz, M. C., Mylon, E., Water, L. L., and Katzenstein, R., Studies on the relation of the kidney to cardiovascular disease. Yale J. Biol. and Med., 1940, 12, 623.

21. Goldblatt, H., Studies on experimental hypertension. The production of the malignant phase of hypertension. J. Exper. Med., 1938, 67, 809.

22. Goldblatt, H., and Kahn, J. R., Studies on experimental hypertension. XIII. Experimental observations on the malignant phase of essential hypertension. The production of intrarenal and extrarenal arteriolar necrosis and necrotizing arteriolitis. Blood, Heart and Circulation. Am. A. Advancement Sc. Pub., No. 13. The Science Press, 1940, page 266.

23. Wilson, C., and Byrom, F. B., Renal changes in malignant hypertension; experimental evidence. Lancet, 1939, 1, 136.

24. Wilson, C., and Byrom, F. B., The vicious circle in chronic Bright's disease. Experimental evidence from hypertensive rat. Quart. J. Med., 1941, 10, 65.

25. Leiter, L., and Eichelberger, L., Pressor kidney extracts ("renin") and the production of cardiac and gastro-intestinal hemorrhages and necroses in dogs with abnormal renal circulation. J. Mt. Sinai Hosp., 1942, 8, 744.

26. Prinzmetal, M., Hiatt, N., and Tragerman, L. J., Hypertension in a patient with bilateral renal infarction; clinical confirmation of experiments in animals. J. A. M. A., 1942, 118, 44.

27. Powers, J. H., and Murray, M. F., Juvenile hypertension associated with unilateral lesions of the upper urinary tract. J. A. M. A., 1942, 118, 600.

28. Schales, O., Hoobler, S. W., and Haynes, F. W., Cardiovascular effects of renin. Proc. Soc. Exper. Biol. and Med., 1941, 48, 720. 